\title{
Understanding how perceptions of tobacco constituents and the FDA relate to effective and credible tobacco risk messaging: A national phone survey of U.S. adults, 2014-2015
}

Marcella H. Boynton 1,2, Robert P. Agans ${ }^{3,4}$, J. Michael Bowling ${ }^{1,2,3,4}$, Noel T. Brewer ${ }^{1,2}$, Erin L. Sutfin ${ }^{6}$, Adam O. Goldstein ${ }^{2,5}$, Seth M. Noar ${ }^{2,7}$ and Kurt M. Ribisl ${ }^{1,2^{*}}$

\begin{abstract}
Background: The passage of the 2009 Family Smoking Prevention and Tobacco Control Act has necessitated the execution of timely, innovative, and policy-relevant tobacco control research to inform Food and Drug Administration (FDA) regulatory and messaging efforts. With recent dramatic changes to tobacco product availability and patterns of use, nationally representative data on tobacco-related perceptions and behaviors are vital, especially for vulnerable populations.

Methods: The UNC Center for Regulatory Research on Tobacco Communication conducted a telephone survey with a national sample of adults ages 18 and older living in the United States (U.S.). The survey assessed regulatory relevant factors such as tobacco product use, tobacco constituent perceptions, and tobacco regulatory agency credibility. The study oversampled high smoking/low income areas as well as cell phone numbers to ensure adequate representation among smokers and young adults, respectively. Coverage extended to approximately $98 \%$ of U.S. households.

Results: The final dataset $(N=5,014)$ generated weighted estimates that were largely comparable to other national demographic and tobacco use estimates. Results revealed that over one quarter of U.S. adults, and over one third of smokers, reported having looked for information about tobacco constituents in cigarette smoke; however, the vast majority was unaware of what constituents might actually be present. Although only a minority of people reported trust in the federal government, two thirds felt that the FDA can effectively regulate tobacco products.
\end{abstract}

Conclusions: As the FDA continues their regulatory and messaging activities, they should expand both the breadth and availability of constituent-related information, targeting these efforts to reach all segments of the U.S. population, especially those disproportionately vulnerable to tobacco product use and its associated negative health outcomes.

Keywords: Tobacco use, Constituents, Cigarette smoking, Non-cigarette tobacco product, Communication

\footnotetext{
* Correspondence: kurt_ribisl@unc.edu

'Department of Health Behavior, Gillings School of Global Public Health,

University of North Carolina at Chapel Hill (UNC), CB \#7440, Chapel Hill, NC

27599-7440, USA

2Lineberger Comprehensive Cancer Center, UNC, CB \#7295, Chapel Hill, NC

27599-7295, USA

Full list of author information is available at the end of the article
}

\section{$\int$ Biomed Central}

(c) 2016 The Author(s). Open Access This article is distributed under the terms of the Creative Commons Attribution 4.0 International License (http://creativecommons.org/licenses/by/4.0/), which permits unrestricted use, distribution, and reproduction in any medium, provided you give appropriate credit to the original author(s) and the source, provide a link to the Creative Commons license, and indicate if changes were made. The Creative Commons Public Domain Dedication waiver (http://creativecommons.org/publicdomain/zero/1.0/) applies to the data made available in this article, unless otherwise stated. 


\section{Background}

Tobacco use is the leading cause of preventable death and disease in the United States (U.S.). Morbidity from smoking-related causes is estimated at more than 480,000 deaths per year, which account for 1 out of 5 deaths in the U.S. [1] Cigarettes, the most commonly used tobacco product by adults, have been causally linked with numerous negative health outcomes, including multiple types of cancer, cardiovascular disease, respiratory ailments, and infection [2]. Although the underlying causes are not wholly clear, members of certain stigmatized and vulnerable groups in the U.S., such as those living in poverty and sexual minorities, are disproportionately affected by these negative tobacco-related consequences [3-5]. One of the major reasons cigarettes are harmful to health is the presence of myriad harmful and potentially harmful constituents in cigarette smoke, many of which are known toxicants or carcinogens [6].

Due to local, state, and national education and policy efforts, cigarette smoking has precipitously decreased from over $42 \%$ of the adult population in 1965-17\% in $2014[7,8]$. In recent years, declines in cigarette smoking have been somewhat offset by increases in use of noncigarette tobacco products (NCTPs), with the greatest uptake primarily observed for adolescents and young adults $[9,10]$. Some NCTPs, such as cigars, have long been available to the public and are a known health hazard. [11] Other products, such as electronic vaping devices, are relatively novel, and as a result have unknown consequences for public health [12]. A growing body of evidence is finding that, like cigarettes, many NCTPs contain harmful and potentially harmful constituents $[11,13,14]$. Considering the substantial health harms of cigarette and NCTP use, more research is needed to inform effective tobacco regulatory and communication efforts.

\section{Tobacco policy and communication}

In 2009, the landmark passage of the Family Smoking Prevention and Tobacco Control Act (FSPTCA) granted the Food and Drug Administration (FDA) the power to regulate tobacco products (Public Law 111-31). Since the passage of the FSPTCA, the FDA has enacted and enforced multiple regulations related to the marketing, manufacturing, and distribution of cigarettes, certain cigarette-related products, and smokeless tobacco. [15] On May 5, 2016 the FDA expanded their regulatory authority to include additional tobacco products, including electronic cigarettes, hookah, and cigars $[16,17]$. As part of their tobacco control efforts, the FDA has implemented education campaigns intended to increase the public's awareness of the potential health harms of tobacco product uptake and use [18].
Many of the tobacco regulatory and education activities performed by the FDA include messaging and communication elements. For example, Sections 904(d) and (e) of the FSPTCA requires the FDA to publish a list of harmful and potentially harmful constituents for each tobacco product, by quantity within each brand and subbrand, in a format that is both understandable and not misleading [19]. Prior research using an online convenience sample of U.S. adults found that although a few tobacco product constituents were familiar to the public (e.g., nicotine, carbon monoxide), the majority of constituents, such as acrolein and tobacco-specific nitrosamines, were generally unknown [20]. Recent qualitative research has not only replicated the finding that the public is largely unaware of the presence of the majority of tobacco constituents in tobacco product smoke or aerosol, but when presented with such information people would often infer meaning and potential harms by relating constituent names to similar-sounding words (e.g., acetaldehyde sounds similar to acetaminophen) [21, 22]. Given that so many constituent names are foreign to the average person, additional research exploring the public's awareness and interest in tobacco constituents is needed to inform whether and how the FDA might best communicate constituent-related information [23].

With the FDA now serving in a pivotal role of communicating the potential harms of tobacco product use, it is essential to understand how both tobacco product users and non-users perceive the credibility of the FDA and U.S. government. Given the tobacco industry's documented targeting of adolescents and other vulnerable groups with potent marketing campaigns [24-26], it is also incumbent upon the FDA to develop and implement messaging optimized to effectively communicate the risks of tobacco use to these populations. Notably, a number of groups most affected by tobacco use and its associated health outcomes have also historically experienced mistreatment by government organizations; examples include individuals with lower levels of education and health literacy, those living in poverty, and sexual minorities [27-30]. Effective risk messaging and product labeling from credible information sources will help ensure that the public, especially vulnerable populations, adequately understand the risks of both tobacco product use and the presence of harmful and potentially harmful constituents.

\section{The current study}

In order to build a base of policy relevant tobacco-related research, the FDA, in partnership with the National Institutes of Health, recently funded 14 Tobacco Centers of Regulatory Science (TCORS). As part of this large research effort, our TCORS Center for Regulatory Research on Tobacco Communication (CRRTC) conducted a nationallyrepresentative phone survey of U.S. adults. The current 
paper reports the methods and sample characteristics from this national phone survey. We compare our demographic and tobacco use estimates to other validated national estimates in order to assess whether our weighted sample is nationally representative. Additionally, we examine the responses for several of the constituent and credibilityrelated items, discussing the implications of the overall estimates as well as differences observed for certain key groups. Taken together the findings lay a foundation for future empirical work that directly informs how perceptions of tobacco constituents and the FDA relate to effective and credible tobacco risk messaging.

\section{Method}

\section{Survey measures}

\section{Development}

Using an iterative survey question generation and revision procedure coordinated among three semi-independent projects, the team developed an instrument assessing tobacco-related product use and perceptions, demographic characteristics, general health, and government organization-related credibility and messaging perceptions. Cognitive interviewing was used at various stages of the measures development process to assess the clarity and construct validity of all new measures.

\section{Translation}

Because English and Spanish are the two most commonly spoken languages in the U.S. [31], the team developed and administered survey measures in both languages. A dual language translation and validation approach was employed using double measures translation with harmonization and validation. Specifically, two professional bilingual translators of differing national origins each independently translated the English language measures. A third fluent Spanish speaker, who served as the translation coordinator and primary measures reviewer, then met with the two translators; through discussion a final version of the Spanish language measures was produced based on the two independent translations. This measures harmonization approach ensured that the Spanish language word usage and syntax was equally accessible to individuals of all Latino and Spanish backgrounds.

\section{Testing}

After the wording and order of the survey questions was finalized, a pilot test of the proposed survey instrument was implemented between August 5 and August 18, 2014. Several independent and non-overlapping convenience samples were used in the pilot $(N=151)$. To oversample smokers, half of the samples targeted low income households earning less than $\$ 25,000$ per year. To boost the number of participants in the pilot who identified as gay, lesbian, or bisexual (GLB), a convenience sample of eleven individuals identifying as GLB were recruited and called as a special batch to test the programming specific to GLB participants. Oversampling of young adults (18-25 years of age) occurred within the household through the application of Poisson sampling techniques where they held higher probabilities of selection. The results of the pilot test were used to inform minor survey item revisions and confirm the accuracy of the survey programming.

\section{Tobacco use measures}

To maximize the fidelity of the tobacco use measures in this study to other national surveys of tobacco product use, many of the tobacco product-related items were taken directly from the Behavioral Risk Factor Surveillance System (BRFSS) questionnaire [32] or from the Population Assessment of Tobacco and Health (PATH) Study [33]. Individuals were classified as current cigarette smokers if they reported having previously smoked at least 100 cigarettes (i.e., five packs) in their lifetime and were currently smoking some days or every day. Smokers were asked about their past 30 day smoking frequency (number of days), menthol cigarette use (none, some, or all cigarettes), cigarette type (e.g., regular, light, ultralight), typical brand (if any), and quit intentions $(0=$ not planning to quit to $3=$ within the next month).

Non-cigarette tobacco product (NCTP) use was also assessed, with descriptions of the various NCTPs provided to respondents. If individuals indicated ever use of a particular NCTP, they were subsequently queried on their frequency of use in the past 30 days. For the current analyses NCTP use is defined as past 30 day use of any of the following: electronic cigarettes or vaping devices, little cigars or cigarillos, hookah, chewing tobacco, snus, premium cigars, or any other tobacco product. Any tobacco use was defined as past 30 day NCTP use or an individual reporting cigarette smoking some days or every day.

\section{Tobacco constituent measures}

A variety of questions related to tobacco constituent information, knowledge, and perceptions were administered. To determine the frequency of informationseeking related to cigarette constituents, participants were asked "Have you ever looked for information on chemicals in cigarettes and cigarette smoke?" As a follow-up question participants were asked "In which 1 of these 3 places would you most like to see information on chemicals in cigarettes and cigarette smoke: on cigarette packs, in stores, or online?" Twenty-four cigarette smoke constituents were selected for assessment by participants. In order to minimize participant burden, the constituents were divided into 6 panels of 4 constituents each, with each participant answering 
questions for one panel (see Appendix A for the list of constituents by panel).

\section{FDA credibility}

Multiple items related to FDA credibility were also administered. Participants were asked whether they had ever heard of the FDA and whether they felt the FDA could "effectively regulate tobacco products." Because sampling efforts were particularly targeted to groups who have historically have been marginalized or exploited by certain U.S. governmental and other authoritative bodies, we also assessed general trust in the government using the item: "How much trust do you have in the federal government?" Responses ranged from $0=$ none at all to $4=$ a great deal .

\section{Demographics}

Characteristics such as gender, age, ethnicity, education, income were assessed primarily using measures from the 2013 BRFSS survey [31] or the 2010 U.S. Census [34]. Race was assessed using the item, "Which one of these groups would you say best represents your race: White, Black or African American, American Indian or Alaska Native, Asian, or Pacific Islander?" Individuals strongly identifying as an unlisted or mixed race were coded as "Other." Education was assessed using an ordinal scale ranging from $0=$ no schooling completed to $15=$ doctorate degree. Numeracy was assessed using a single item adapted from a standard numeracy scale [35]: "In general, which of these numbers shows the biggest risk of getting a disease: 1 in 100, 1 in 1000, or 1 in 10?" Poverty level was determined using the household size and income reported by the respondents and applying the federal poverty numbers available from the U.S. Department of Health and Human Services in 2014. The sexual orientation measure was developed using guidelines provided by the Williams Institute [36], which asked "Do you consider yourself to be (A) straight or heterosexual, (B) gay or lesbian, or $(\mathrm{C})$ bisexual?"

\section{Sampling and recruitment}

Two independent and non-overlapping random digit dialing frames were used in this study with approximately $98 \%$ coverage of all U.S. adult households [37]. To oversample smokers, both frames were stratified by household income and smoking rates at the county-level, where the poorest counties with the highest smoking rates were oversampled. Concordant with prior national tobacco survey studies [38], we oversampled cell phones numbers to maximize counts of young adults. To be considered eligible, a telephone number needed to reach a household with an English- or Spanish-speaking resident 18 years of age or older. Within the landline frame, if more than one eligible adult resided in the household, young adults and smokers were sampled at a higher rate than older adult nonsmokers.
The national survey was conducted between September 15, 2014 and May 31, 2015 and had an average completion time of $25 \mathrm{~min}$. Calls were made Saturday through Thursday between 9 am and 9 pm (local time). Blaise CATI software [39] was used to both manage the sample and collect the data. No numbers were removed from calling until a minimum of 6 (cell phone) to 8 (landline) unsuccessful call attempts were made with at least one weekend, evening, and daytime call attempt. The sample resulted in 5,014 interviews and a weighted response rate (calculated using AAPOR Response Rate 4) of $42 \%$, a rate which is comparable to the 2012-2013 National Adult Tobacco Survey (44.9\%) [40] and the 2012 BRFSS (45.3\%) [41]. The remaining sample consisted of ineligible numbers $(64,410)$, refusals from eligible households $(2,623)$, or indeterminable eligibility status $(41,877)$. All interviewers completed general and project-specific training before conducting the surveys and were monitored twice fortnightly. Informed consent for participation in the study was obtained verbally from respondents at the time of enrollment. The IRB at the University of North Carolina approved all study procedures and respondents were protected by a certificate of confidentiality.

\section{Sampling weights and adjustments}

A standard three-step sample weighting procedure was followed to produce sampling weights [42]. The base weights were computed using the sampling rate for telephone numbers in each stratum, adjusting for the number of eligible respondents and landline telephone numbers in the household as well as any oversampling of young adults and/or smokers that might have occurred in the landline sample (Step 1). The base weights were then adjusted for differential household-level nonresponse among sampling strata using the inverse of the stratum-specific householdlevel response rate as the adjustment factor (Step 2). The nonresponse-adjusted household sample weight was then calibrated to population counts as estimated from the American Community Survey [34] sample by implementing the SAS rake and trimming macro [43] on the following variables: census region, age (18-24, 25-44, 45-64, or $\geq 65$ ), education ( $\leq$ high school, some college, or bachelor's degree and higher), gender, ethnicity (Hispanic or non-Hispanic), phone-type (cell or landline) and regional smoking rates. Final weights were normalized to the total sample size [44].

\section{Analysis}

All analyses were conducted using SAS version 9.3 and took the sample design features into account. Weighted sample means and proportions with $95 \%$ confidence intervals incorporating both sampling weight and strata variables were computed using the PROC SURVEYMEANS and PROC SURVEYFREQ procedures. Stratum-specific weighted analyses by subgroup (e.g., smokers, young 
adults) employed the BY command for the PROC SURV EYMEANS procedure and the TABLE command for the PROC SURVEYFREQ procedure. Weighted analyses of intra-group differences for categorical variables (i.e., comparisons between smokers vs. non-smokers, young adults vs. older adults, etc.) employed $\chi^{2}$ tests using the CHISQ command. For the continuously scaled trust in the federal government variable, means were generated using PROC SURVEYMEANS and intra-group comparisons were made using PROC SURVEYREG.

\section{Results}

\section{Demographics}

Examination of the weighted estimates revealed a weighted proportion of $50.8 \%$ females and an age range of 18 to 95 years $(M=45.9, S D=17.3)$. The two largest racial groups in this sample were White (68.3\%) and Black/African American (18.3\%). Approximately $14 \%$ of the sample identified as Latino or Hispanic. Young adults (i.e., individuals aged 18-24) comprised $12.7 \%$ of the sample and, based on reported household size and annual income, $14.3 \%$ of the sample was identified as living below the U.S. federal poverty line. In addition, $3.2 \%$ of the sample identified as GLB.

In order to assess the quality of our sampling design we compared this study's weighted demographic estimates to comparable national point estimates, thereby providing a sense of the relative "representativeness" of our weighted sample. As can been seen in Table 1, across a wide range of demographic factors the majority of estimates from other national surveys or the U.S. Census fall within the $95 \%$ confidence intervals (CI) of the sample's weighted point estimates. The only noteworthy exceptions were race and ethnicity, which slightly overestimates the proportions of Whites and African Americans and slightly underestimates the proportions of Asians and Latinos. In each case, the difference between the national estimate and the relevant confidence interval bound was no more than 3.5 percentage points.

\section{Tobacco product use}

As a result of the oversampling strategy employed in this study, smokers represented $23.0 \%(N=1151)$ of the unweighted sample; however, at $17.8 \%$ the weighted smoking prevalence for the entire sample was effectively identical to the national prevalence estimate (see Table 1). The national estimate for any tobacco product use $(25.2 \%)$, which encompassed both cigarette and NCTP use, was within one percentage point of the lower bound of the $95 \% \mathrm{CI}$ for our estimate of $28.4 \%$ [40]. Table 2 presents the weighted proportion of smokers for key demographic characteristics. Most of the estimates for our sample fell within the CIs of the U.S. Census or other national estimates, with the remainder falling within 2 percentage points of either the upper or lower confidence bound.
Consistent with the literature, smoking rates were notably higher for respondents reporting less education, low literacy, and living below the federal poverty line. Furthermore, cigarette smoking was relatively higher for GLBs, Native Americans, and NCTP users, a finding also concordant with prior research [8]. The only notable differences between our estimates and other national estimates of tobacco use were among Black (vs. White) and Latinos (vs. non-Latinos), which were modestly overestimated.

Table 3 presents cigarette use characteristics for the smokers. The majority (73.5 \%) reported smoking every day in the past 30 days. A little over a third of respondents $(38.8 \%)$ reported only smoking menthols in the past 30 days, and another $15.8 \%$ smoked some menthols during that time. Regular or full flavor cigarettes were the most commonly smoked type (58.5\%), followed by light or mild, (29.4\%). The Centers for Disease Control and Prevention (CDC) estimates for the top four cigarette brands in the U.S. are $41 \%$ Marlboro, $12 \%$ Newport, 8 \% Pall Mall, and 8 \% Camel [45]. Our weighted estimates were largely equivalent: Marlboro, 38.2 \%, CI [32.7, 43.7], Newport, $20.1 \%$, CI [15.9, 24.3], Pall Mall, 7.0 \%, CI [4.0, 9.9], and Camel, $6.3 \%$, CI $[4.1,8.4]$. Notably, a majority of smokers (81.5\%) reported planning to quit sometime in the future.

\section{Differences in constituent and FDA-related perceptions by vulnerable groups \\ Constituent information}

Table 4 presents tobacco constituent communication findings. More than a quarter of adults $(27.5 \%)$ reported having looked for information on tobacco constituents. Of those, higher proportions of smokers (34.3\%) and young adults (37.2 \%) had previously looked for this information, as compared to non-smokers $(26.1 \%, p=.004)$ and older adults $(26.0 \%, p<.0001)$, respectively. A smaller proportion of individuals with low education reported having previously looked for information on tobacco constituents $(22.2 \%)$ as compared to those with greater educational attainment than a high school diploma $(31.5 \%, p<.0001)$.

When asked where they would most like to see information on tobacco constituents, over half indicated that they would prefer it on cigarette packs (54.8 \%) and another quarter most wanted the information available online $(28.7 \%)$. There was no difference between smokers and non-smokers for information location preference; however, as compared to older adults (27.4\%), a higher proportion of young adults preferred that constituent information be available online $(38.2 \%, p=.0003)$.

Over one third of U.S. adults were not aware that any of the four constituents in their survey panel were present in cigarette smoke (37.5\%), and only $8 \%$ knew that at least three of the constituents in their survey panel are present in cigarette smoke. Constituent awareness was lower for 
Table 1 Demographic characteristics as compared to U.S. Census and other national surveys, CRRTC national adult ( $\geq 18$ years) phone survey 2014-2015

\begin{tabular}{|c|c|c|c|c|}
\hline \multirow{3}{*}{$\overline{\text { Gender }}$} & \multirow{2}{*}{$\frac{\text { Unweighted }}{\%(n)}$} & \multicolumn{2}{|c|}{ Weighted } & \multirow{2}{*}{$\begin{array}{l}\text { National estimate } \\
\%\end{array}$} \\
\hline & & $\%$ & $95 \% \mathrm{Cl}$ & \\
\hline & & & & \\
\hline & $47.3 \%(2372)$ & $48.5 \%$ & $(46.0-51.0)$ & $49.2 \%[34]$ \\
\hline Female & $52.7 \%(2640)$ & $51.5 \%$ & $(49.0-54.0)$ & $50.8 \%$ [34] \\
\hline Age, years & $45.9 \pm 17.3$ & 46.7 & $(45.8-47.7)$ & \\
\hline \multicolumn{5}{|l|}{ Age category } \\
\hline $18-24$ & $14.2 \%(711)$ & $12.7 \%$ & $(11.2-14.1)$ & $13.1 \%[34]$ \\
\hline $25-44$ & $32.3 \%(1612)$ & $33.2 \%$ & $(30.8-35.5)$ & $35.0 \%[34]$ \\
\hline $45-64$ & $37.7 \%(1883)$ & $36.7 \%$ & $(34.3-39.1)$ & $34.7 \%[34]$ \\
\hline $65+$ & $15.8 \%(789)$ & $17.5 \%$ & $(15.3-19.6)$ & $17.2[34]$ \\
\hline \multicolumn{5}{|l|}{ Race } \\
\hline White & $69.7 \%(3473)$ & $68.3 \%$ & $(65.9-70.6)$ & $62.6 \%[34]$ \\
\hline Black or African American & $19.6 \%(978)$ & $18.3 \%$ & $(16.3-20.3)$ & $13.2 \%[34]$ \\
\hline American Indian or Alaska Native & $2.7 \%(135)$ & $1.9 \%$ & $(1.3-2.6)$ & $1.2 \%[34]$ \\
\hline Asian & $2.1 \%(104)$ & $2.4 \%$ & $(1.8-3.1)$ & $5.3 \%[34]$ \\
\hline Pacific Islander & $0.4 \%(21)$ & $0.8 \%$ & $(0.3-1.3)$ & $0.2 \%[34]$ \\
\hline Other or Unknown & $5.4 \%(270)$ & $8.2 \%$ & $(6.8-9.7)$ & \\
\hline \multicolumn{5}{|l|}{ Ethnicity } \\
\hline Latino/Hispanic & $8.6 \%(432)$ & $14.2 \%$ & $(12.4-16.0)$ & $17.1 \%[34]$ \\
\hline Non-Latino/Hispanic & $91.4 \%(4568)$ & $85.8 \%$ & $(84.0-87.6)$ & $82.9 \%[34]$ \\
\hline \multicolumn{5}{|l|}{ Education } \\
\hline$<$ High school (HS) & $10.5 \%(524)$ & $11.2 \%$ & $(9.2-13.2)$ & $12.3 \%[34]$ \\
\hline G12 or GED, HS diploma & $24.7 \%(1232)$ & $31.4 \%$ & $(28.8-34.0)$ & $29.6 \%[34]$ \\
\hline Some college & $20.7 \%(1034)$ & $20.7 \%$ & $(18.8-22.6)$ & $19.4 \%[34]$ \\
\hline Associate's degree & $9.9 \%(496)$ & $10.5 \%$ & $(9.0-12.0)$ & $9.4 \%[34]$ \\
\hline Bachelor's degree & $21.2 \%(1060)$ & $15.7 \%$ & $(14.3-17.1)$ & $18.9 \%[34]$ \\
\hline Graduate or professional degree & $13.0 \%(651)$ & $10.5 \%$ & $(9.4-11.6)$ & $10.4 \%[34]$ \\
\hline \multicolumn{5}{|l|}{ Numeracy } \\
\hline Incorrect or "do not know" numeracy response & $32.0 \%(1599)$ & $31.9 \%$ & $(29.5-34.3)$ & \\
\hline Correct numeracy response & $68.0 \%(3401)$ & $68.1 \%$ & $(65.7-70.5)$ & $75.3 \%[53]$ \\
\hline \multicolumn{5}{|l|}{ Household Poverty } \\
\hline At or above federal poverty level & $84.0 \%(3901)$ & $85.7 \%$ & $(83.8-87.5)$ & $84.6 \%[34]$ \\
\hline Below federal poverty level & $16.0 \%(745)$ & $14.3 \%$ & $(12.5-16.2)$ & $15.4 \%[34]$ \\
\hline \multicolumn{5}{|l|}{ Sexual Orientation } \\
\hline Straight or heterosexual & $94.3 \%(4730)$ & $94.2 \%$ & $(93.1-95.3)$ & \\
\hline Gay, lesbian, or bisexual & $3.8 \%(192)$ & $3.2 \%$ & $(2.5-3.8)$ & $3.5 \%[54]$ \\
\hline Other or refused & $1.8 \%(92)$ & $2.6 \%$ & $(1.7-3.5)$ & \\
\hline \multicolumn{5}{|l|}{ Census Region } \\
\hline Northeast & $10.7 \%(537)$ & $18.2 \%$ & $(16.3-20.2)$ & $17.9 \%[34]$ \\
\hline Midwest & $19.4 \%(972)$ & $21.5 \%$ & $(19.3-23.8)$ & $21.7 \%[34]$ \\
\hline South & $53.6 \%(2685)$ & $37.1 \%$ & $(34.7-39.5)$ & $37.1 \%$ [34] \\
\hline West & $16.3 \%(819)$ & $23.1 \%$ & $(21.1-25.1)$ & $23.3 \%$ [34] \\
\hline
\end{tabular}


Table 1 Demographic characteristics as compared to U.S. Census and other national surveys, CRRTC national adult ( $\geq 18$ years) phone survey 2014-2015 (Continued)

\begin{tabular}{|c|c|c|c|c|}
\hline \multicolumn{5}{|l|}{ Tobacco Product Use } \\
\hline Any tobacco product use, past 30 days & $32.6 \%(1633)$ & $28.4 \%$ & $(26.2-30.6)$ & \multirow[t]{2}{*}{$25.2 \%[40]$} \\
\hline No tobacco product use, past 30 days & $67.4 \%(3381)$ & $71.6 \%$ & $(69.4-73.8)$ & \\
\hline \multicolumn{5}{|l|}{ Current cigarette smoking } \\
\hline Current smoker & $23.0 \%(1151)$ & $17.8 \%$ & $(16.0-19.6)$ & \multirow[t]{3}{*}{$18.0 \%[40]$} \\
\hline Non-smoker & $77.0 \%(3856)$ & $82.2 \%$ & $(80.4-84.0)$ & \\
\hline Used $\geq 1$ NCTP in past 30 days & $20.4 \%(1022)$ & $18.6 \%$ & $(16.7-20.5)$ & \\
\hline
\end{tabular}

[34] US Census 2013-2014 [53]; Galesic \& Garcia-Retamero (2010) [54]; Gallup 2013 LGBT poll [40]; CDC's National Adult Tobacco Survey, Tobacco Product Use Among Adults — United States, 2012-2013

the low educational attainment $(p<.0001)$ and low numeracy groups $(p=.02)$, with over $75 \%$ of both subgroups not aware of more than 1 constituent in their survey panel being present in cigarette smoke.

\section{FDA credibility}

The vast majority of U.S. adults (94.6\%) reported having heard of the FDA, although awareness was lower for young adults $(90.9 \%, p=.007)$, those with low education ( $89.7 \%$, $p<.0001)$, those with low numeracy $(91.7 \%, p=.0009)$, and those living in poverty $(87.5 \%, p<.0001)$. The majority of both smokers $(66.6 \%)$ and non-smokers $(65.0 \%)$ believed that the FDA can effectively regulate tobacco products. The proportions of people endorsing effective FDA tobacco product regulation were even higher for young adults $(79.3 \%, p<.0001)$ and GLBs $(76.3 \%, p=.04)$. Of note, young adults were much more likely to identify as GLB as compared to older adults, $\chi^{2}(1)=21.5, p<.0005$.

In stark contrast to the relative support of the FDA, less than half of U.S. adults (42.9 \%) reported feeling some trust in the federal government (i.e., a rating of $3=a$ fair amount or $4=a$ great deal). On average, smokers reported less trust in the federal government $(M=1.7)$ as compared to nonsmokers, $(M=2.0, p<.0001)$. Additionally, individuals living in poverty had greater trust in the government $(M=2.2)$ as compared to those not living in poverty, $(M=2.0, p=.004)$.

\section{Discussion}

The passage of the 2009 FSPTCA promised to usher in a new era in tobacco regulation that has enormous implications for improving public health. The funding of 14 TCORS is an important advancement in the field of tobacco regulatory science, with the national phone survey detailed herein offering relevant and timely data that can inform FDA policy and messaging efforts. The survey had a response rate of $42 \%$, which is on par with other national tobacco surveys. We found that our weighted tobacco use estimates mirrored CDC estimates and U.S. demographic estimates largely fell within the confidence bounds of our sample's weighted estimates. These finding indicate that our sample weights appropriately adjusted our estimates to reflect those of the U.S. population. These encouraging findings pave the way for additional analyses of data from this dataset, especially as relevant to perceptions of tobacco product constituents, FDA credibility, and tobacco communication.

Because tobacco product marketing and tobacco-related health outcomes disproportionally impact younger and marginalized communities as well as those with a history of tobacco use, we chose to strategically oversample individuals from these groups. Comparisons between the unweighted and weighted estimates in Table 1 showed that we successfully oversampled smokers and young adults as well as achieved comparable proportions for individuals with low educational attainment and those living in poverty-a noteworthy achievement given that these groups tend to be under-represented in national surveys [46]. By obtaining robustly sized sub-samples, it was possible to generate stable group estimates for key groups on a number of tobacco constituent and FDA credibility-related perceptions.

Examination of the constituent-related measures showed that the majority of the U.S. public would like ready access to tobacco constituent information. In fact, our results reveal that groups one might presume to be the least psychologically motivated to search for tobacco constituent information, young adults and smokers, were most likely to say that they had previously looked for this information. Moreover, more than $80 \%$ of U.S. smokers report intending to eventually quit smoking, suggesting that many smokers are in the contemplation stage of behavior change and would therefore benefit from greater access to constituent information [47]. Taken together, these findings indicate that the legislatively mandated publication of tobacco constituent information is of great interest to the public, and if executed well, could improve public health. Our results also showed that different groups may prefer different channels of information. For example, older adults preferred constituent information on cigarette packs whereas young adults equally preferred it on packs and online. Given these results, the FDA may want to consider making constituent information available through multiple channels.

Although nearly one third of U.S. adults have actively sought out information about tobacco constituents, the 
Table 2 Percentage of smokers by selected demographic characteristics, CRRTC national adult ( $\geq 18$ years) phone survey $2014-2015$

\begin{tabular}{|c|c|c|c|c|}
\hline \multirow{3}{*}{ Gender } & \multicolumn{2}{|c|}{ Weighted } & \multicolumn{2}{|c|}{ National estimate } \\
\hline & \multirow[t]{2}{*}{$\%$} & \multirow[t]{2}{*}{$95 \% \mathrm{Cl}$} & \multirow[t]{2}{*}{$\%$} & \multirow[t]{2}{*}{$95 \% \mathrm{Cl}$} \\
\hline & & & & \\
\hline & $18.6 \%$ & $(16.1-21.1)$ & $18.8 \%$ & $(18.0-19.7)$ \\
\hline Female & $17.0 \%$ & $(14.4-19.7)$ & $14.8 \%$ & $(14.0-15.7)$ \\
\hline \multicolumn{5}{|l|}{ Age category } \\
\hline $18-24$ & $15.4 \%$ & $(11.6-22.4)$ & $16.7 \%$ & $(14.0-19.3)$ \\
\hline $25-44$ & $22.3 \%$ & $(18.7-26.0)$ & $20.0 \%$ & $(19.1-21.0)$ \\
\hline $45-64$ & $19.5 \%$ & $(16.4-22.5)$ & $18.0 \%$ & $(17.0-19.1)$ \\
\hline $65+$ & $7.8 \%$ & $(5.0-10.5)$ & $8.5 \%$ & $(7.7-9.3)$ \\
\hline \multicolumn{5}{|l|}{ Race } \\
\hline White & $17.6 \%$ & $(15.4-19.8)$ & $18.2 \%$ & $(18.6-20.2)$ \\
\hline Black or African American & $21.6 \%$ & $(16.7-26.4)$ & $17.5 \%$ & $(16.1-18.8)$ \\
\hline American Indian or Alaska Native & $26.7 \%$ & $(12.9-40.4)$ & $29.2 \%$ & $(19.7-38.7)$ \\
\hline Asian & $6.5 \%$ & $(2.1-10.9)$ & $9.5 \%$ & $(7.7-11.2)$ \\
\hline \multicolumn{5}{|l|}{ Pacific Islander } \\
\hline Other or Unknown & $16.6 \%$ & $(10.7-22.4)$ & $26.8 \%$ & $(21.9-31.8)$ \\
\hline \multicolumn{5}{|l|}{ Ethnicity } \\
\hline Latino/Hispanic & $18.7 \%$ & $(16.7-20.7)$ & $11.2 \%$ & $(11.0-13.2)$ \\
\hline Non-Latino/Hispanic & $12.7 \%$ & $(8.7-16.7)$ & & \\
\hline \multicolumn{5}{|l|}{ Education } \\
\hline$<$ High school (HS) & $25.8 \%$ & $(18.7-32.8)$ & $22.9 \%$ & $(21.3-24.5)$ \\
\hline G12 or GED, HS diploma & $21.9 \%$ & $(18.2-25.6)$ & $21.7 \%$ & $(20.3-23.0)$ \\
\hline Some college & $22.3 \%$ & $(17.6-27.1)$ & $19.7 \%$ & $(18.3-21.1)$ \\
\hline Associate's degree & $17.4 \%$ & $(12.6-22.2)$ & $17.1 \%$ & $(14.5-19.6)$ \\
\hline Bachelor's degree & $8.2 \%$ & $(5.9-10.4)$ & $7.9 \%$ & $(7.1-8.8)$ \\
\hline Graduate or professional degree & $3.5 \%$ & $(1.8-5.2)$ & $5.4 \%$ & $(4.5-6.3)$ \\
\hline \multicolumn{5}{|l|}{ Numeracy } \\
\hline Incorrect or "do not know" numeracy response & $21.4 \%$ & $(18.0-24.7)$ & & \\
\hline Correct numeracy response & $16.1 \%$ & $(13.9-18.3)$ & & \\
\hline \multicolumn{5}{|l|}{ Household Poverty } \\
\hline At or above federal poverty level & $15.4 \%$ & $(13.5-17.3)$ & $15.2 \%$ & $(14.6-15.9)$ \\
\hline Below federal poverty level & $29.3 \%$ & $(23.9-34.7)$ & $29.2 \%$ & $(27.5-31.0)$ \\
\hline \multicolumn{5}{|l|}{ Sexual Orientation } \\
\hline Straight or heterosexual & $17.5 \%$ & $(15.7-19.4)$ & $17.6 \%$ & $(16.9-18.2)$ \\
\hline Gay, lesbian, or bisexual & $24.4 \%$ & $(16.1-32.6)$ & $26.3 \%$ & $(24.6-28.1)$ \\
\hline Other or refused & $18.8 \%$ & $(3.1-34.5)$ & & \\
\hline \multicolumn{5}{|l|}{ Census Region } \\
\hline Northeast & $16.9 \%$ & $(12.2-21.7)$ & $15.3 \%$ & $(13.9-16.7)$ \\
\hline Midwest & $20.6 \%$ & $(15.8-25.4)$ & $20.7 \%$ & $(18.9-22.4)$ \\
\hline South & $19.2 \%$ & $(16.5-21.9)$ & $17.2 \%$ & $(16.3-18.1)$ \\
\hline West & $13.6 \%$ & $(10.6-16.6)$ & $13.1 \%$ & $(12.1-14.2)$ \\
\hline Used $\geq 1$ NCTP in past 30 days & $44.1 \%$ & $(38.8-49.4)$ & & \\
\hline
\end{tabular}

National estimates taken from Jamal et al., 2014 [8] 
Table 3 Current smoker cigarette use characteristics, adults $\geq$ 18 years, CRRTC national adult phone survey 2014-2015

\begin{tabular}{|c|c|c|}
\hline & \multicolumn{2}{|c|}{ Weighted estimates } \\
\hline & $\%$ & $95 \% \mathrm{Cl}$ \\
\hline Number of days smoked in the past 30 days & $25.3[0-30]$ & $(24.5-26.1)$ \\
\hline \multicolumn{3}{|l|}{ Past 30 day smoking frequency } \\
\hline 0 days & $0.8 \%$ & $(0.3-1.4)$ \\
\hline 1 or 2 days & $2.2 \%$ & $(1.0-3.3)$ \\
\hline 3 to 5 days & $5.8 \%$ & $(3.6-7.9)$ \\
\hline 6 to 9 days & $1.9 \%$ & $(0.6-3.3)$ \\
\hline 10 to 19 days & $7.9 \%$ & $(5.4-10.5)$ \\
\hline 20 to 29 days & $7.9 \%$ & $(3.4-12.3)$ \\
\hline All 30 days & $73.5 \%$ & $(68.3-78.7)$ \\
\hline \multicolumn{3}{|l|}{ Past 30 day menthol use } \\
\hline All cigarettes smoked were menthols & $38.8 \%$ & $(33.0-44.6)$ \\
\hline Some cigarettes smoked were menthols & $15.8 \%$ & $(11.9-19.7)$ \\
\hline No cigarettes smoked were menthols & $45.5 \%$ & $(40.0-50.9)$ \\
\hline \multicolumn{3}{|l|}{ Cigarette Type } \\
\hline Regular or full flavor & $58.5 \%$ & $(53.3-63.7)$ \\
\hline Light or mild & $29.4 \%$ & $(24.3-34.5)$ \\
\hline Ultra light & $7.3 \%$ & $(4.7-9.9)$ \\
\hline Other or unspecified & $4.8 \%$ & $(2.4-7.3)$ \\
\hline \multicolumn{3}{|l|}{ Cigarette Brand } \\
\hline Marlboro & $38.2 \%$ & $(32.7-43.7)$ \\
\hline Newport & $20.1 \%$ & $(15.9-24.3)$ \\
\hline Pall Mall & $7.0 \%$ & $(4.0-9.9)$ \\
\hline Camel & $6.3 \%$ & $(4.1-8.4)$ \\
\hline$L \& M$ & $3.2 \%$ & $(1.7-4.6)$ \\
\hline Maverick & $2.6 \%$ & $(0.2-5.0)$ \\
\hline Pyramid & $2.6 \%$ & $(0.2-1.6)$ \\
\hline American Spirit & $1.6 \%$ & $(0.7-2.5)$ \\
\hline Kool & $1.5 \%$ & $(0.6-2.5)$ \\
\hline Virginia Slims & $0.9 \%$ & $(1.3-3.3)$ \\
\hline Doral & $0.8 \%$ & $(0.2-1.4)$ \\
\hline Salem & $0.8 \%$ & $(0.1-1.2)$ \\
\hline Winston & $0.7 \%$ & $(1.8-5.5)$ \\
\hline Parliament & $0.6 \%$ & $(0.1-1.5)$ \\
\hline Benson \& Hedges & $0.4 \%$ & $(0.0-0.9)$ \\
\hline Generic or least expensive & $2.3 \%$ & $(3.3-7.0)$ \\
\hline Roll your own & $3.7 \%$ & $(0.0-0.9)$ \\
\hline Other brand & $6.8 \%$ & $(4.8-8.9)$ \\
\hline \multicolumn{3}{|l|}{ Quit Intentions } \\
\hline Within the next month & $23.4 \%$ & $(18.8-27.9)$ \\
\hline Within the next 6 months & $24.8 \%$ & $(19.4-30.2)$ \\
\hline Sometime in the future beyond 6 months & $32.3 \%$ & $(27.4-37.2)$ \\
\hline Not planning to quit & $19.5 \%$ & $(15.7-23.3)$ \\
\hline
\end{tabular}

public appears to still be largely unaware of what constituents are contained in cigarette smoke. In the current study, we asked respondents whether they had heard that each of 4 constituents are in cigarette smoke.. As there were six different panels, we ultimately obtained data on 24 unique constituents, all of which appear on the FDA's full list of 93 harmful and potentially harmful cigarette smoke constituents [48]. With the exception of nicotine, most people were largely unaware of what constituents are present in cigarette smoke. Over one third of respondents were unaware that even one of their listed constituents were present in cigarette smoke, and another third only reported knowing one of their four as being present in cigarette smoke. Future FDA messaging efforts could benefit from including information about the presence and health implications of tobacco constituents.

The data presented herein indicate that for most U.S. adults the FDA is a known entity that is capable of regulating tobacco. In stark contrast, the majority of people in the U.S. report low levels of trust in the "federal government." In other words, although FDA is a part of the federal government, individuals may not typically think of it as such. Thus, in certain cases identifying the FDA as the source of a counter tobacco message may help to increase the credibility and impact of the message.

\section{Limitations and future directions}

The current study's strengths include the recruitment of a large, nationally representative sample, targeted oversampling of key vulnerable groups, and the development of psychometrically valid health, tobacco use, and constituent communication items administered in both English and Spanish. Our study largely focused on constituents for which the FDA has signaled that they are most likely to require tobacco manufacturers to report quantity information [49]. However, with well over 5,000 chemicals in tobacco products [6] and 93 that the FDA has already identified as harmful or potentially harmful [48], future messaging efforts will likely expand to include an array of different constituents. Although our findings are consistent with past research showing low levels of awareness for the presence of the majority of constituents in cigarette smoke, future studies exploring awareness of a wider range of constituents would be informative, especially once the FDA releases constituent information for tobacco products. A second limitation is that the unique associations between GLB status, age, and tobacco-related perceptions are somewhat difficult to disentangle because, as compared to older adults, young adults more likely to identify as GLB. There is a great need for more tobacco control research with those who identify as GLB, especially considering that this population has a substantially higher tobacco use rate as compared to their non-GLB peers [50]. 
Table 4 Subset of communication-related variables - CRRTC national adult phone survey 2014-2015

\begin{tabular}{|c|c|c|c|c|c|c|c|}
\hline & \multicolumn{7}{|c|}{ Weighted proportion or $M$ with $95 \%$ confidence interval } \\
\hline & Total & Smokers & Young adults & Low education & Low numeracy & Living in poverty & GLBS \\
\hline \multicolumn{8}{|l|}{ Information Seeking } \\
\hline \multicolumn{8}{|c|}{ Have you ever looked for information on chemicals in cigarettes and cigarette smoke? } \\
\hline Yes & $27.5 \%(25.4-29.7)$ & $34.3 \%(28.8-39.8)$ & $37.2 \%(31.6-42.8)$ & $22.2 \%(18.6-25.7)$ & $26.7 \%(22.7-30.6)$ & $25.7 \%(19.7-31.6)$ & $30.1 \%(21.0-39.1)$ \\
\hline No & $72.5 \%(70.3-74.6)$ & $65.7 \%(60.2-71.2)$ & $62.8 \%(57.2-68.4)$ & $77.8 \%(74.3-81.4)$ & $73.3 \%(69.4-77.3)$ & $74.3 \%(68.4-80.3)$ & $69.9 \%(60.9-79.0)$ \\
\hline \multicolumn{8}{|c|}{ In which 1 of these 3 places would you most like to see information on chemicals in cigarettes and cigarette smoke? } \\
\hline On cigarette packs & $54.8 \%(52.4-57.3)$ & $57.2 \%(51.9-62.6)$ & $46.8 \%(40.9-52.6)$ & $55.4 \%(50.9-60.0)$ & $53.9 \%(49.5-58.3)$ & $54.3 \%(47.4-61.2)$ & $46.9 \%(36.4-57.3)$ \\
\hline In stores & $15.0 \%(13.2-16.7)$ & $11.6 \%(7.9-15.3)$ & $14.7 \%(10.7-18.7)$ & $16.8 \%(13.6-20.0)$ & $16.0 \%(12.9-19.2)$ & $18.3 \%(13.2-23.5)$ & $17.2 \%(10.3-24.1)$ \\
\hline Online & $28.7 \%(26.5-30.9)$ & $28.8 \%(24.2-33.4)$ & $38.2 \%(32.5-43.8)$ & $26.2 \%(22.3-30.0)$ & $28.5 \%(24.6-32.5)$ & $25.5 \%(19.7-31.4)$ & $35.8 \%(26.1-45.4)$ \\
\hline $\begin{array}{l}\text { Don't know, refused, or doesn't } \\
\text { want information }\end{array}$ & $1.5 \%(0.9-2.08)$ & $2.4 \%(1.0-3.7)$ & $0.2 \%(0.0-0.8)$ & $1.6 \%(0.5-2.7)$ & $1.5 \%(0.56-2.46)$ & $1.8 \%(0.3-3.3)$ & $0.1 \%(0.0-0.3)$ \\
\hline \multicolumn{8}{|l|}{ Constituent Awareness } \\
\hline Aware of 0 of 4 constituents in cigarette smoke & $37.5 \%(35.0-40.1)$ & $36.7 \%(31.6-41.8)$ & $32.7 \%(27.3-38.2)$ & $46.4 \%(28.9-37.2)$ & $42.9 \%(38.4-47.4)$ & $43.1 \%(35.7-50.4)$ & $31.3(22.0-40.7)$ \\
\hline Aware of 1 of 4 constituents in cigarette smoke & $35.8 \%(33.4-38.2)$ & $41.2 \%(35.6-46.9)$ & $36.1 \%(30.4-41.7)$ & $33.1 \%(35.4-40.9)$ & $34.5 \%(30.3-38.7)$ & $34.7 \%(28.2-41.2)$ & $38.9(28.5-49.3)$ \\
\hline Aware of 2 of 4 constituents in cigarette smoke & $18.7 \%(16.7-20.7)$ & $15.8 \%(12.2-19.4)$ & $22.7 \%(17.9-27.6)$ & $14.5 \%(19.1-23.6)$ & $16.0 \%(12.9-19.2)$ & $13.6 \%(9.8-17.5)$ & $18.2(11.0-25.4)$ \\
\hline Aware of 3 of 4 constituents in cigarette smoke & $5.6 \%(4.6-6.5)$ & $3.4 \%(1.9-4.8)$ & $5.9 \%(3.4-8.4)$ & $3.3 \%(5.9-8.6)$ & $4.8 \%(3.3-6.3)$ & $5.7 \%(3.0-8.4)$ & $9.3(3.0-15.7)$ \\
\hline Aware of 4 of 4 constituents in cigarette smoke & $2.4 \%(1.7-3.1)$ & $3.0 \%(0.5-5.4)$ & $2.5 \%(0.6-4.5)$ & $2.8 \%(1.5-2.9)$ & $1.8 \%(0.8-2.9)$ & $2.9 \%(0.8-5.1)$ & $2.3(0.0-5.0)$ \\
\hline \multicolumn{8}{|c|}{ Knowledge of and Trust for FDA and U.S. Federal Government } \\
\hline \multicolumn{8}{|c|}{ Have you ever heard of the FDA or Food and Drug Administration? } \\
\hline Yes & $94.6 \%(93.4-95.8)$ & $95.4 \%(93.0-95.8)$ & $90.9 \%(87.7-94.2)$ & $89.7 \%(87.0-92.3)$ & $91.7 \%(89.0-94.3)$ & $87.5 \%(83.0-92.0)$ & $91.7 \%(85.0-98.3)$ \\
\hline No & $5.4 \%(4.2-6.6)$ & $4.6 \%(2.5-6.8)$ & $9.1 \%(5.8-12.3)$ & $10.3 \%(7.7 \%-13.0)$ & $8.3 \%(5.7-11.0)$ & $12.5 \%(8.0-17.0)$ & $8.3 \%(1.7-15.0)$ \\
\hline \multicolumn{8}{|l|}{ Can the FDA effectively regulate tobacco products? } \\
\hline Yes & $65.2 \%(62.6-67.8)$ & $66.6 \%(61.2-72.0)$ & $79.3 \%(74.7-83.9)$ & $64.9 \%(59.9-69.9)$ & $62.1 \%(57.4-66.9)$ & $67.8 \%(61.3-74.1)$ & $76.3 \%(67.1-85.4)$ \\
\hline No & $34.8 \%(32.2-37.4)$ & $33.4 \%(26.9-37.4)$ & $20.7 \%(74.7-83.9)$ & $35.1 \%(31.9-37.5)$ & $37.9 \%(33.1-42.6)$ & $32.2 \%(25.8-38.7)$ & $23.7 \%(14.6-32.9)$ \\
\hline $\begin{array}{l}\text { How much trust do you have in the } \\
\text { federal government? } M \text { score, } 0=\text { none } \\
\text { at all - } 4=a \text { great deal }\end{array}$ & $2.0(1.9-2.0)$ & $1.7(1.6-1.8)$ & $2.1(2.0-2.2)$ & $1.9(1.8-2.0)$ & $2.0(1.8-2.1)$ & $2.2(2.0-2.4)$ & $2.1(1.9-2.4)$ \\
\hline
\end{tabular}

Note. Point estimates in bold text were found to be significantly different from their respective comparison group (e.g., smokers were compared to non-smokers, young adults compared to older adults, etc.) using either PROC SURVEYFREQ or PROC SURVEYREG to make the comparisons 
Future analyses of our adult phone survey data will examine several key tobacco communication issues, and portions of the survey will be repeated in two years' time to examine potential temporal changes. One important area meriting further exploration is how the U.S. public perceives tobacco product use in the context of learning about constituents in cigarettes and NCTPs. In other words, there are a wide range of possible constituents that the FDA could message on; it would be instructive to explore whether certain types of constituents have a greater or lesser impact on tobacco use risk perceptions. Relatedly, given the highly technical names of many onstituent names, it would be of value to examine what contextual information might be important to include with constituent disclosures to make clear the risks associated with their presence in cigarettes and NCTPs (e.g., what health effects are caused by particular constituents).

Another critical tobacco communication issue is the public's perceptions of tobacco messaging agencies and their public health campaigns [51], especially as related to perceived source credibility [52]. Our preliminary findings indicate that different vulnerable groups have varied perceptions of the sources of tobacco health messages (e.g., FDA, CDC), suggesting that the source of messages may need to be emphasized in different ways, depending on the target audience. Future research that delves into the cognitive mechanisms underlying these group differences in government organization credibility would be informative.

\section{Conclusions}

As the FDA moves forward with its tobacco policy and communication efforts, the positive impact on tobacco perceptions and use can be maximized by incorporating empirical evidence considering issues such as constituent perceptions and tobacco regulatory agency messaging credibility. Additional national survey work in the U.S. context is needed in order to monitor the public's response to FDA communications as well as to identify changing patterns of tobacco-related perceptions and use, especially for vulnerable populations.

\section{Abbreviations}

BRFSS, behavioral risk factor surveillance system; CDC, centers for disease control and prevention; $\mathrm{Cl}, 95 \%$ confidence interval; CRRTC, center for regulatory research on tobacco communication; FDA, U.S. food and drug administration; FSPTCA, family smoking prevention and tobacco control act; GLB, gay, lesbian, or bisexual; NCTP(s), noncigarette tobacco product(s); PATH, population assessment of tobacco and health; TCORS, tobacco centers of regulatory science; U.S., United States of America

\section{Acknowledgements}

The research and manuscript preparation were supported by $\mathrm{NIH}$ grant P50 CA180907. Its contents are solely the responsibility of the authors and do not necessarily represent the official views of NIH or the FDA. The authors extend their profound appreciation to Quirina Vallejos, Jennifer Mendel, Kimberly Wiseman, Leah Ranney, and Kristen Jarmen for project management, Anna Hoffmeyer for coordination of participant enrollment and survey center activities, and Deborah Marean for survey programming.

\section{Availability of data and materials}

The data described herein come from a nationally-representative phone survey of U.S. adults collected by our TCORS Center for Regulatory Research on Tobacco Communication. We are unable to make the data available at this time because a public use dataset has not yet been created.

\section{Authors' contributions}

MHB participated in design of the survey measures and methods, facilitated survey implementation, performed all data analyses, and drafted the manuscript. RPA assisted with the survey design, managed survey programming and implementation, and helped draft portions of the manuscript. JMB designed and implemented the sampling methodology. NTB, ES, AG, and SMN were the primary individuals responsible for measures development. KMR conceived of the study, participated in its design and coordination, and helped to draft the manuscript. All authors read and approved the final manuscript.

\section{Competing interests}

The authors declare that they have no competing interests.

\section{Consent for publication}

Not Applicable.

\section{Ethics approval and consent to participate}

The institutional review board (IRB) at the University of North Carolina approved all study procedures. Participants were also protected by a Certificate of Confidentiality granted by the National Institutes of Health. Informed consent for participation in the study was obtained verbally from respondents at the time of enrollment.

\section{Author details}

'Department of Health Behavior, Gillings School of Global Public Health, University of North Carolina at Chapel Hill (UNC), CB \#7440, Chapel Hill, NC 27599-7440, USA. ${ }^{2}$ Lineberger Comprehensive Cancer Center, UNC, CB \#7295, Chapel Hill, NC 27599-7295, USA. ${ }^{3}$ Carolina Survey Research Laboratory, UNC, 730 Martin Luther King Jr Blvd, Chapel Hill, NC 27514, USA. ${ }^{4}$ Department of

\section{Appendix A}

Table 5 Constituent panels

\begin{tabular}{|c|c|c|c|c|}
\hline Constituent Panel & Constituent 1 & Constituent 2 & Constituent 3 & Constituent 4 \\
\hline 1 & lead & toluene & 1-aminonaphthalene & crotonaldehyde \\
\hline 2 & nicotine & hydrogen cyanide & isoprene & acrylonitrile \\
\hline 3 & formaldehyde & benzo-a-pyrene & napthalene & NNK \\
\hline 4 & arsenic & benzene & acrolein & 2-aminonaphthalene \\
\hline 5 & carbon monoxide & uranium & 1,3-butadiene & $\mathrm{N}$-nitrosonornicotine \\
\hline 6 & ammonia & acetaldehyde & nitrosamine & 4-aminobiphenyl \\
\hline
\end{tabular}


Biostatistics, Gillings School of Global Public Health, CB \#74203101 McGavran-Greenberg Hall, Chapel Hill, NC 27599-7420, USA. ${ }^{5}$ Department of Family Medicine, School of Medicine, UNC, CB \#7595Manning Drive, Chapel Hill, NC 27599-7595, USA. ${ }^{6}$ Department of Social Sciences and Health Policy, Wake Forest School of Medicine, Medical Center Boulevard, Winston-Salem, NC 27157, USA. ${ }^{7}$ School of Media and Journalism, UNC, CB \#3365, Chapel Hill, NC 27599-7440, USA.

\section{Received: 2 February 2016 Accepted: 25 May 2016}

Published online: 23 June 2016

\section{References}

1. U.S. Surgeon General. The health consequences of smoking - 50 years of progress: a report of the Surgeon General. U.S. Department of Health and Human Services, Centers for Disease Control and Prevention, National Center for Chronic Disease Prevention and Health Promotion, Office on Smoking and Health. 2014. http://www.surgeongeneral.gov/library/reports/ 50-years-of-progress/full-report.pdf. Accessed on 21 Jan 2016.

2. Carter BD, Freedman ND, Jacobs EJ. Smoking and mortality-beyond established causes. N Engl J Med. 2015;372(22):2170. doi:10.1056/ nejmsa1407211.

3. Fagan P, King G, Lawrence D, et al. Eliminating tobacco-related health disparities: Directions for future research. Am J Public Health. 2004;94(2): 211-7. doi:10.2105/AJPH.94.2.211.

4. Ward E, Jemal A, Cokkinides $V$, et al. Cancer disparities by race/ethnicity and socioeconomic status. CA Cancer J Clin. 2004;54(2):78-93. doi:10.3322/ canjclin.54.2.78.

5. Garrett BE, Dube SR, Babb S, et al. Addressing the social determinants of health to reduce tobacco-related disparities. Nicotine Tob Res. 2015;17(8): 892-7. doi:10.1093/ntr/ntu266.

6. Talhout R, Schulz T, Florek E, van Benthem J, Wester P, Opperhuizen A. Hazardous compounds in tobacco smoke. Int J Environ Res Public Health. 2011;8(2):613-28. doi:10.3390/ijerph8020613.

7. Office on Smoking and Health, National Center for Chronic Disease Prevention and Health Promotion. Trends in current cigarette smoking among high school students and adults, United States. Centers for Disease Control and Prevention. 1965-2011. 2013. http://www.cdc.gov/tobacco/ data_statistics/tables/trends/cig_smoking/. Accessed on 21 Jan 2016.

8. Jamal A, Homa DM, O'Connor E, Babb SD, Caraballo RS, et al. Current cigarette smoking among adults - United States, 2005-2014. Centers for Disease Control and Prevention. 2015. http://www.cdc.gov/mmwr/preview/ mmwrhtml/mm6444a2.htm?s_cid=mm6444a2_w. Accessed on 21 Jan 2016

9. Gilreath TD, Leventhal A, Barrington-Trimis JL, et al. Patterns of alternative tobacco product use: Emergence of hookah and e-cigarettes as preferred products amongst youth. J Adolesc Health. 2015;doi:10. 1016/j.jadohealth.2015.10.001

10. O'Connor RJ. Non-cigarette tobacco products: What have we learned and where are we headed? Tob Control. 2012;21(2):181-190. doi:10.1136/ tobaccocontrol-2011-050281.

11. National Cancer Institute. Cigars: health effects and trends. Smoking and Tobacco Control Monograph No. 9. Bethesda (MD): National Institutes of Health, National Cancer Institute; 1998.

12. Lopez AA, Eissenberg T. Science and the evolving electronic cigarette. Prev Med. 2015;80:101-6. doi:10.1016/j.ypmed.2015.07.006.

13. Shihadeh A, Schubert J, Klaiany J, et al. Toxicant content, physical properties and biological activity of waterpipe tobacco smoke and its tobacco-free alternatives. Tob Control. 2015;24 Suppl 1:i22-30. doi:10.1136/ tobaccocontrol-2014-051907.

14. Hecht SS, Carmella SG, Kotandeniya D, et al. Evaluation of toxicant and carcinogen metabolites in the urine of e-cigarette users versus cigarette smokers. Nicotine Tob Res. 2015;17(6):704-9. doi:10.1093/ntr/ntu218.

15. Zeller M. Progress and Challenges: The State of Tobacco Use and Regulation in the U.S. 2014. http://www.fda.gov/NewsEvents/Testimony/ ucm397399.htm Accessed on 21 Jan 2016.

16. U.S. Food and Drug Administration. FDA takes significant steps to protect Americans from dangers of tobacco through new regulation. http://www. fda.gov/NewsEvents/Newsroom/PressAnnouncements/ucm499234.htm Accessed on 6 May 2016

17. U.S. Food and Drug Administration. Deeming Tobacco Products To Be Subject to the Federal Food, Drug, and Cosmetic Act, as Amended by the Family Smoking Prevention and Tobacco Control Act; Restrictions on the Sale and
Distribution of Tobacco Products and Required Warning Statements for Tobacco Products. https://www.federalregister.gov/articles/2016/05/10/201610685/deeming-tobacco-products-to-be-subject-to-the-federal-food-drug-andcosmetic-act-as-amended-by-the Accessed on 6 May 2016.

18. U.S. Food and Drug Administration, Center for Tobacco Products. Public Education Campaigns http://www.fda.gov/tobaccoproducts/ publichealtheducation/publiceducationcampaigns/default.htm Accessed on 21 Jan 2016.

19. Family Smoking Prevention and Tobacco Control Act. http://www.fda.gov/ TobaccoProducts/GuidanceComplianceRegulatoryInformation/ucm237092. htm 2009. Accessed on 21 Jan 2016.

20. Hall MG, Ribisl KM, Brewer NT. Smokers' and nonsmokers' beliefs about harmful tobacco constituents: implications for FDA communication efforts. Nicotine Tob Res. 2014;16(3):343-50. doi:10.1093/ntr/ntt158.

21. Moracco KE, Morgan JC, Mendel J, Teal R, Noar SM, Ribisl KM, Brewer NT. "My first thought was croutons:" Perceptions of cigarettes and cigarette smoke constituents among adult smokers and nonsmokers. Nicotine Tob Res. 2015. doi:10.1093/ntr/ntv281.

22. Wiseman KD, Cornacchione J, Wagoner KG, Noar SM, Moracco KE, Teal R, Sutfin, EL. Adolescents' and young adults' knowledge and beliefs about constituents in novel tobacco products. Nicotine Tob Res. 2016. doi:10. 1093/ntr/ntw009.

23. Hammond D. Tobacco packaging and labeling policies under the U.S. Tobacco Control Act: Research needs and priorities. Nicotine Tob Res. 2012; 14(1):62-74. doi:10.1093/ntr/ntr182.

24. Pierce JP, Gilpin EA. A historical analysis of tobacco marketing and the uptake of smoking by youth in the United States: 1890-1977. Health Psychol. 1995;14(6):500-8. doi:10.1037/0278-6133.14.6.500.

25. Cruz TB, Wright LT, Crawford G. The menthol marketing mix: targeted promotions for focus communities in the United States. Nicotine Tob Res. 2010;12 Suppl 2:S147-53. doi:10.1093/ntr/ntq201.

26. Stevens $P$, Carlson LM, Hinman JM. An analysis of tobacco industry marketing to lesbian, gay, bisexual, and transgender (LGBT) populations: Strategies for mainstream tobacco control and prevention. Health Promot Pract. 2004;5:129S-34.

27. O'Keefe EB, Meltzer JP, Bethea TN. Health disparities and cancer: racial disparities in cancer mortality in the United States, 2000-2010. Front Public Health. 2015;3:51. doi:10.3389/fpubh.2015.00051.

28. Meza R, Meernik C, Jeon J, et al. Lung cancer incidence trends by gender, race and histology in the United States, 1973-2010. PLoS One. 2015;10(3), e0121323. doi:10.1371/journal.pone.0121323.

29. Emory $K$, Kim $Y$, Buchting $F$, et al. Intragroup variance in lesbian, gay, and bisexual tobacco use behaviors: Evidence that subgroups matter, notably bisexual women. Nicotine Tob Res. 2015. doi:10.1093/ntr/ntv208.

30. Hiscock R, Bauld L, Amos A, et al. Socioeconomic status and smoking: a review. Ann N Y Acad Sci. 2012;1248:107-23. doi:10.1111/j.1749-6632.2011.06202.x.

31. Language Use in the United States: 2011 American Community Survey Reports. https://www.census.gov/prod/2013pubs/acs-22.pdf Accessed on 21 Jan 2016.

32. Centers for Disease Control. 2013 Behavioral risk factor surveillance system questionnaire. http://www.cdc.gov/brfss/questionnaires/pdf-ques/ 2013\%20brfss_english.pdf Accessed on 21 Jan 2016.

33. National Institutes of Health, Instruments for Wave 2 of the PATH Study. http://www.reginfo.gov/public/do/PRAViewlC?ref_nbr=201407-0925004\&iclD=212557 Accessed on 21 Jan 2016.

34. US Census. American Community Survey United States Census Bureau. http://www.census.gov/acs Accessed on 21 Jan 2016.

35. Lipkus IM, Samsa G, Rimer BK. General performance on a numeracy scale among highly educated samples. Med Decis Making. 2001;21(1):37-44. doi: 10.1177/0272989X0102100105.

36. The Williams Institute. Best practices for asking questions about sexual orientation on surveys. http://williamsinstitute.law.ucla.edu/wp-content/ uploads/SMART-FINAL-Nov-2009.pdf. Accessed on 21 Jan 2016.

37. Blumberg SJ, Luke C. Early release of estimates from the National Health Interview Survey, July-December 2013. Hyattsville, MD, USA: National Center for Health Statistics. 2014.

38. Gundersen DA, ZuWallack RS, Dayton J, et al. Assessing the feasibility and sample quality of a national random-digit dialing cellular phone survey of young adults. Am J Epidemiol. 2014;179(1):39-47. doi:10.1093/aje/kwt226.

39. Blaise [computer program]. Version 4.8. Voorburg/Heerlen: Statistics Netherlands. 2008 
40. Agaku IT, King BA, Husten CG, et al. Tobacco Product Use Among Adults - United States, 2013-2013. Centers for Disease Control and Prevention: Atlanta; 2014. http://www.cdc.gov/mmwr/preview/ mmwrhtml/mm6325a3.htm. Accessed on 21 Jan 2016

41. Behavioral Risk Factor Surveillance System. 2013 Summary Data Quality Report: Center for Disease Control and Prevention, Atlanta; August 15, 2014. http://www.cdc.gov/brfss/annual_data/annual_2013.html. Accessed on 21 Jan 2016.

42. Kalsbeek W, Agans R. Sampling and weighting in household telephone surveys. In: Lepkowski J, Tucker C, Brick J, et al., editors. Advances in telephone survey methodology. New York: Wiley \& Sons; 2008.

43. Battaglia M, Hoaglin DC, Frankel, MR. Practical considerations in raking survey data. Survey Practice (Online Journal). 2009; 2(5).

44. Flores-Cervantes I, Kalton G. Methods for sampling rare populations in telephone surveys. In: Lepkowski J, Tucker C, Brick J, et al., editors. Advances in telephone survey methodology. New York: Wiley \& Sons; 2008.

45. Centers for Disease Control and Prevention. Tobacco brand preferences: 2014. http://www.cdc.gov/tobacco/data_statistics/fact_sheets/tobacco_ industry/brand_preference/. Accessed on 21 Jan 2016.

46. Biener L, Garrett CA, Gilpin EA, et al. Consequences of declining survey response rates for smoking prevalence estimates. Am J Prev Med. 2004; 27(3):254-7. doi:10.1016/j.amepre.2004.05.006.

47. Prochaska JO, DiClemente CC, Norcross JC. In search of how people change. Applications to addictive behaviors. Am Psychol. 1992;47:1102-14. doi:10.1037/0003-066X.47.9.1102.

48. Food and Drug Administration. Harmful and potentially harmful constituents in tobacco products and tobacco smoke: Established list. http://www.fda.gov/ TobaccoProducts/GuidanceComplianceRegulatoryInformation/ucm297786. htm. Accessed on 21 Jan 2016.

49. U.S. Department of Health and Human Services, Food and Drug Administration, Center for Tobacco Products (CTP). Guidance for industry reporting harmful and potentially harmful constituents in tobacco products and tobacco smoke under section 904(a)(3) of the Federal Food, Drug, and Cosmetic Act, DRAFT GUIDANCE. http://www.fda.gov/downloads/ TobaccoProducts/Labeling/RulesRegulationsGuidance/ucm297828.pdf

50. Johnson SE, Holder-Hayes E, Tessman GK, et al. Tobacco product use among sexual minority adults: findings from the 2012-2013 national adult tobacco survey. Am J Prev Med. 2015. doi:10.1016/j.amepre.2015.07.041.

51. Duke JC, Alexander TN, Zhao X, Delahanty JC, Allen JA, MacMonegle AJ, Farrelly, MC. Youth's awareness of and reactions to the real cost national tobacco public education campaign. PLoS One. 2015;10:e0144827. doi:10. 1371/journal.pone.0144827.

52. Schmidt AM, Ranney LM, Pepper JK, Goldstein AO. Source credibility in tobacco control messaging. Tob Regul Sci. 2016;2(1):31-7. doi:10.18001/TRS.2.1.3.

53. Galesic M, Garcia-Retamero R. Statistical numeracy for health: A crosscultural comparison with probabilistic national samples. Arch Intern Med. 2010;170(5):462-8. doi:10.1001/archinternmed.2009.481.

54. Gates JG, Newport F. LGBT percentage highest in D.C., lowest in North Dakota. Gallup. 2013. http://www.gallup.com/poll/160517/lgbt-percentagehighest-lowest-north-dakota.aspx Accessed on 21 Jan 2016.

\section{Submit your next manuscript to BioMed Central and we will help you at every step:}

- We accept pre-submission inquiries

- Our selector tool helps you to find the most relevant journal

- We provide round the clock customer support

- Convenient online submission

- Thorough peer review

- Inclusion in PubMed and all major indexing services

- Maximum visibility for your research

Submit your manuscript at www.biomedcentral.com/submit 